\title{
Is phrenic nerve conduction affected in patients with difficult-to-treat asthma?
}

\author{
A neurocondução do nervo frênico está alterada na asma de difícil controle? \\ Analúcia Abreu Maranhão,,2, Marcia Maria Jardim Rodrigues', Sonia Regina da Silva Carvalho \\ Marcelo Ribeiro Caetano ${ }^{3}$, Inaê Mattoso Compagnoni4, Tatiana Catia Carnio 4 , Débora Ribeiro ${ }^{4}$
}

\begin{abstract}
Objective: The aim of this study was to obtain data on phrenic neuroconduction and electromyography of the diaphragm muscle in difficult-to-treat asthmatic patients and compare the results to those obtained in controls. Methods: The study consisted of 20 difficultto-treat asthmatic patients compared with 27 controls. Spirometry, maximal inspiratory and expiratory pressure, chest X-ray, phrenic neuroconduction and diaphragm electromyography data were obtained. Results: The phrenic compound motor action potential area was reduced, compared with controls, and all the patients had normal diaphragm electromyography. Conclusion: It is possible that a reduced phrenic compound motor action potential area, without electromyography abnormalities, could be related to diaphragm muscle fiber abnormalities due to overload activity.
\end{abstract}

Keywords: electrodiagnosis; phrenic nerve; spirometry; neural conduction; asthma.

\section{RESUMO}

Objetivo: O objetivo do presente estudo foi obter dados da neurocondução do frênico e exame com agulha do diafragma em pacientes com asma de difícil controlee comparar com um grupo normal. Métodos: 0 estudo consiste em realizar radiografia de tórax, espirometria, pressão máxima inspiratória e expiratória, neurocondução do nervo frênico e eletromiografia do músculo diafragma em 20 pacientes asmáticos de difícil controle e comparar com 27 controles. Resultados: Encontramos redução da área do potencial de ação muscular composto do nervo frênico e a eletromiografia do musculo diafragma estava normal em todos os pacientes. Conclusão: É possível que a redução da área do potencial de ação muscular composto do nervo frênico nos pacientes com asma de difícil controle associado a eletromiografia normal do músculo diafragma esteja relacionada as alterações da fibra muscular do mesmo devido à sobrecarga de atividade.

Palavras-chave: eletrodiagnóstico; nervo frênico; espirometria; condução nervosa; asma.

The most recent definition of asthma is that it is a heterogeneous disease, usually characterized by chronic airway inflammation, defined by a history of chronic respiratory symptoms that vary over time, both in frequency and intensity, and associated with variable airflow limitation ${ }^{1}$.

The majority of patients with asthma can be treated effectively with the currently available medications.

However, a significant proportion of patients labeled as "difficult-to-treat asthma" or "severe refractory asthma" remain a challenge for the treating clinician. Severe refractory asthma encompasses a variety of sub phenotypes of asthma that do not respond to the current standard therapy, i.e. high doses of inhaled corticosteroids in combination with longacting $\beta 2$-agonists ${ }^{23}$.
Difficult-to-treat asthma, while affecting only $5-10 \%$ of the asthma population, is associated with the greatest share of asthma morbidity and economic burden ${ }^{4}$. This clinical problem still exists despite many advances in the understanding of the underlying basis of asthma and improved management strategies, which include targeted anti-inflammatory therapy with monoclonal antibodies. Research effort continues, with exploration of different aspects of pathophysiology such as genomics, proteomics, inflammation, airway remodeling and airway smooth muscle abnormalities ${ }^{5}$.

Common etiologies of chronic hypercapnic respiratory failure include severe airway disorders [e.g., chronic obstructive pulmonary disease (COPD) and asthma], chest wall abnormalities, and neuromuscular diseases. Spirometry is

'Universidade Federal do Estado Rio de Janeiro, Faculdade de Medicina, Programa de Pós-Graduação em Neurologia, Rio de Janeiro RJ, Brasil;

${ }^{2}$ Universidade Federal do Estado Rio de Janeiro, Faculdade de Medicina, Departamento de Pneumologia, Rio de Janeiro RJ, Brasil;

${ }^{3}$ Universidade Federal do Estado Rio de Janeiro, Faculdade de Medicina, Departamento de Neurocirurgia, Rio de Janeiro RJ, Brasil.

${ }^{4}$ Undergraduate, Faculty of Medicine, Rio de Janeiro State Federal University, Rio de Janeiro, Brazil.

Correspondence: Analúcia A. Maranhão; Rua Maris e Barros, 775; 20270-001, Rio de Janeiro RJ, Brasil; E-mail: aamaranhao66@gmail.com

Conflict of interest: There is no conflict of interest to declare.

Received 15 October 2017; Received in final form 23 November 2017; Accepted 18 December 2017. 
essential for the diagnosis of COPD, asthma and assessment of disease severity. To confirm the diagnosis, clinical assessment and imaging studies are used ${ }^{6}$. By contrast, disorders of the diaphragm or its innervation are thought to be a relatively rare cause of respiratory failure. Nevertheless, in patients with hypercapnic respiratory failure, this group of neuromuscular disorders should always be considered, especially in patients with no other explanation for their symptoms. Innervated by the phrenic nerve, the diaphragm is the principal respiratory muscle in humans.

To demonstrate a neuromuscular cause of hypercapnic respiratory failure, respiratory electrodiagnostic studies are often used. It is important to carry out phrenic nerve conduction studies to differentiate neuromuscular disorders from other causes of hypercapnic respiratory failure, particularly asthma and $\mathrm{COPD}^{7}$.

The aim of this study was to obtain data on phrenic nerve conduction studies and needle electromyography (EMG) of the diaphragm muscle in asthmatic patients and compare the results to those obtained in controls. This information is expected to be useful for the diagnosis of neuromuscular disorders in patients with severe asthma.

\section{METHODS}

A group of 20 asthmatics and 27 control individuals were studied. The asthmatic patients were recruited from the pulmonary ambulatory clinic of the Gaffree and Guinle University Hospital. Neurologic disorders, diabetes mellitus, or any systemic or endocrinal disease affecting the nervous system were exclusion criteria. From 102 asthmatic patients, 27 were classified as difficult-to-treat, five of whom were excluded due to diabetes, and two refused to participate. None of them were an active smoker. Neurological examination, especially proximal muscular strength was evaluated in all of them. The inclusion criteria for difficultto-treat asthma were the requirement of treatment within guidelines of suggested medications in the Global initiative for asthma (GINA) steps 4-5 for the previous year, or systemic corticosteroids for greater than or equal to $50 \%$ of the previous year to prevent the asthma from becoming "uncontrolled", or which remains "uncontrolled" despite this therapy ${ }^{8}$. The characteristics of the 20 patients were as follows: four men and 16 women, 37-74 years old (mean 57.65 years old), height, $145-170 \mathrm{~cm}$ (mean, $158 \mathrm{~cm}$ ); weight, $51-105 \mathrm{~kg}$ (mean, $75.5 \mathrm{~kg}$ ).

Controls had normal spirometry tests and chest X-rays. Respiratory and neuromuscular disorders were excluded. The characteristics of the 27 controls were as follows: 15 men and 12 women, 21-62 years old (mean, 30 years) height, 155-186 cm (mean, $171 \mathrm{~cm}$ ); weight, 52-100/ kg (mean, $73 \mathrm{~kg}$ ). They were recruited from students and employees of the university hospital (with different degrees of physical activity). The study was approved by the Gaffree and Guinle University Hospital Ethics Committee, and all participants provided informed consent.

The spirometry test procedure used the forced vital capacity (FVC) technique in which the participant performs a full inspiration and then a forceful expiration, as rapidly and completely as possible. Each participant performed, in the sitting position, at least three trials and the best performance was used for analysis. An adequate test required a minimum of three acceptable FVC maneuvers. The test was considered acceptable when the difference between the largest and the next largest

FVC and the first second of forced expiratory volume (FEV1) was 0.150 L or less ${ }^{9}$.

The Knudson prediction equations were used for the time-volume and flow-volume curves ${ }^{10}$. Parameters analyzed were: FVC, FEV1 and the FEV1/FVC ratio.

The Spiron (Physis, Rio de Janeiro, Brazil) spirometer was used.

Postero-anterior and lateral chest X-ray films were obtained at maximal inspiration. The radiographs were acquired by a trained radiographer and were read by the chest physician. For analysis, the highest values of maneuvers with variability less than $10 \%$ were used. In our study, maximal respiratory pressure measurements were performed according to Brazilian guidelines ${ }^{11}$.

The phrenic neuroconduction was performed with participants lying in a supine position. Supraclavicular stimulation was attempted between the sternal and clavicular heads and behind the sternocleidomastoid muscle with a bipolar stimulating electrode (Neurosoft, Ivanovo, Russia) ${ }^{12,13}$. We used two disposable self-adhesive disk recording electrodes (Viasys Healthcare, Madison, Wisconsin). The active electrode (G1) was fixed $5 \mathrm{~cm}$ above the xiphoid process, and the reference electrode (G2) $16 \mathrm{~cm}$ from G1, on the chest margin ipsilateral to the stimulated phrenic nerve. An electromyography system (Neuro-MEP-Micro, Neurosoft, Ivanovo, Russia) with standard settings ( filters: $2 \mathrm{~Hz}$ to $10 \mathrm{kHz}$ ) was used. The gain was set to $0.5 \mathrm{mv}$ and the sweep speed to $2 \mathrm{~ms} / \mathrm{div}$. Bilateral studies were performed on all participants. Electrical stimulation was carried out with rectangular pulses of $0.1 \mathrm{~ms}$ or $0.2 \mathrm{~ms}$ duration. Measurements were made separately during normal inspiration and expiration. The phrenic nerve compound muscle action potential (CMAP) onset latency, amplitude, duration and area of the negative phase were obtained at supramaximal stimulation, 10-20\% above maximal stimulation (Figure 1). An electrophysiological work-up for exclusion of peripheral neuropathy was carried out and included sensory conduction studies of sural and superficial peroneal nerves, and motor conduction studies of posterior tibial and deep peroneal nerves.

Inspiratory CMAP is sharper with a shorter duration and increased amplitude compared to expiratory CMAP. CMAP: compound muscle action potential. 
A standard disposable concentric EMG needle electrode with a recording area of $0.07 \mathrm{~mm}^{2}$, diameter of $0.46 \mathrm{~mm}^{2}$, and lengths of $37 \mathrm{~mm}$ and $50 \mathrm{~mm}$ (DCN37 and DCN50, respectively; Medtronic Functional Diagnostics, Skovlunde, Denmark), and an EMG system (Neuro-MEP-Micro, Neurosoft, Ivanovo, Russia) with standard settings ( filters, $5 \mathrm{~Hz}$ to $10 \mathrm{kHz}$ ) were used. A needle electrode was inserted into the medial recess of the right seventh, eighth, or ninth intercostal space. During slow advancement of the needle electrode through the tissues, we carefully observed and listened to the EMG signal. Rhythmic bursts of low-amplitude motor unit potentials during inspiration and absent EMG activity during expiration confirmed that the electrode tip had reached the diaphragm. At that point, with EMG activity during normal breathing, rest activity and motor unit potentials were analyzed.

The control group comprised 27 healthy participants and the disease group comprised 20 participants who are affected by asthma. The normality was tested in all studied variables by the Shapiro Wilk test using the R platform (free software) and SPSS. All variables that showed a non-normal distribution at a 5\% significance level were analyzed using a non-parametric approach. For these variables, the Wilcoxon test was used, while the t-test was used for normal variables. Age, weight, FVC, FVC\%, FEV1, FEV1\%, FEV1/FVC had p-values under $5 \%$ or were close to it (FEV1\%). Therefore, for analytical purposes, a non-parametric approach was taken for these, as they were not considered normally distributed.

\section{RESULTS}

The variables FEV1\%, FVC, FEV1, FEV1/FVC, FVC\%, age, height, expiratory CMAP area, expiratory CMAP duration and inspiratory CMAP area showed significant differences between the groups (control and disease). The results of the hypothesis tests and method are shown in the Table according to normality and in order of significance. The Table also shows the mean and confidence interval (CI) at 95\% for normal variables; and median, $5 \%$ or $95 \%$ for non-normal distributions. The differences between the control and disease groups are illustrated in Figure 2. Boxplots represent nonnormally distributed variables and the plot of means with 95\% CI represents normally distributed variables. The variables that did not have a significant difference between the two groups were amplitude and latency. Mean expiratory CMAP amplitude was: $0.58 \mathrm{mv}$ (disease group) and $0.65 \mathrm{mv}$ (control group), mean inspiratory CMAP amplitude was: 0.74 $\mathrm{mv}$ (disease group) and $0.89 \mathrm{mv}$ (control group), mean expiratory CMAP latency was $6.05 \mathrm{~ms}$ (disease group) and 6.42 ms (control group) and mean inspiratory CMAP latency was: $5.90 \mathrm{~ms}$ (disease group) and $6.12 \mathrm{~ms}$ (control group). Five asthmatic patients had abnormal CMAP amplitudes and only one had an abnormal CMAP latency.

The ten significant differences at $5 \%$ are represented against normality by a plot of means with $95 \%$ confidence interval and Boxplot. With exception of age, all the variables in the graph showed lower values in the diseased group. FEV1: forced expiratory volume in one second; EXP: expiratory; FVC: forced vital capacity.

Both electrophysiologic (expiratory CMAP area, expiratory CMAP duration and inspiratory CMAP area) and spirometric (FEV1\%, FVC, FEV1, FEV1/FVC, FVC\%) tests seemed to decrease significantly due to the presence of the disease. But there are some limitations to this conclusion. Age and gender were significantly different between groups. The disease group was older and there were only four males in this group. Gender differences between groups was evaluated by chi-squared test ( $\mathrm{p}=0.01406$ ). Age and gender between control and disease groups might influence the conclusions

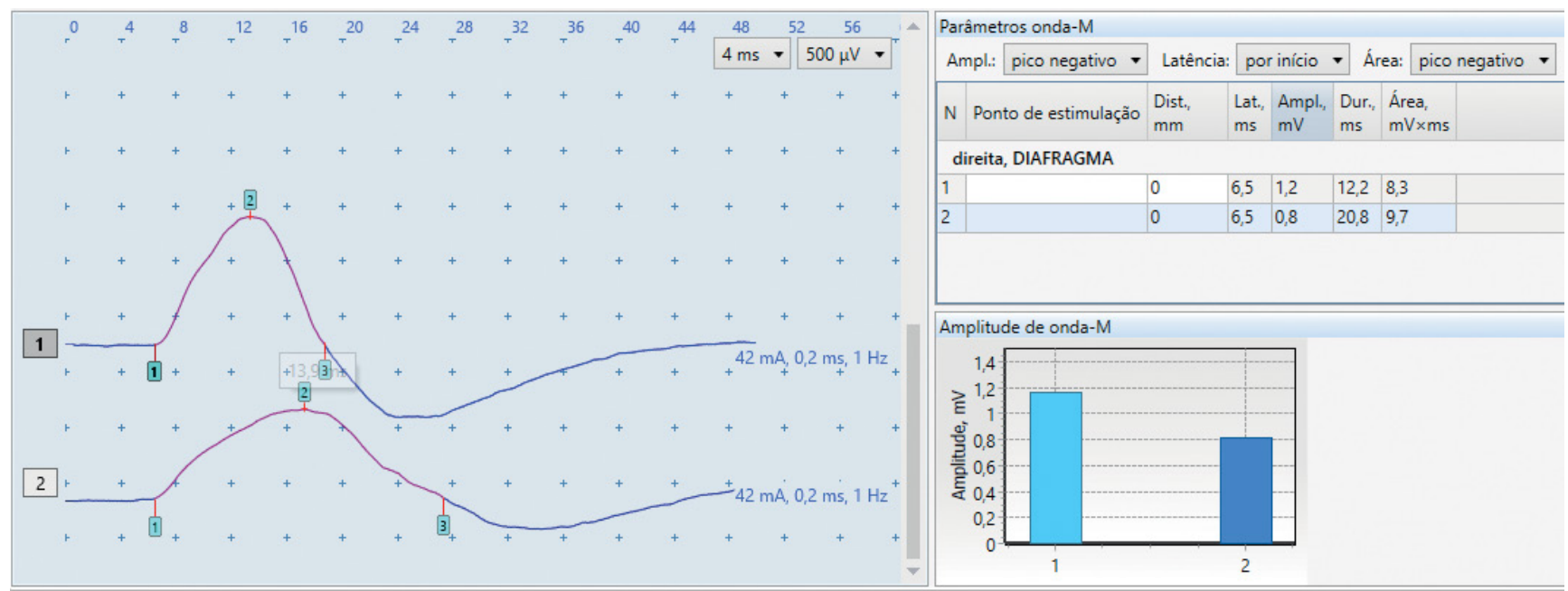

CMAP: compound muscle action potential.

Figure 1. Inspiratory CMAP is sharper with a shorter duration and increased amplitude compared to expiratory CMAP. 
made about differences in these groups due to lack of balance in the samples obtained for these factors. Height differences were also significant and may be explained by gender differences and also might have influenced the differences shown in the analyses.

The electromyography studies of all 20 asthmatic patients were normal at rest (absence of positive waves, fibrillation potentials and discharges) and visual analysis of recruitment and motor unit potentials was not myopathic or neurogenic. The neurological examination, including proximal muscular strength, was normal in the disease group.

\section{DISCUSSION}

Difficult-to-treat asthma is a challenge, even for experienced pulmonologists. The possibility of diaphragmatic muscle impairment in these patients has never been studied through EMG and phrenic nerve neuroconduction. Although COPD is a chronic lower respiratory airway obstruction with a different pathologic mechanism for asthma, we can suppose that these two conditions may share some diaphragm muscle fiber abnormalities, as both induce a chronic overload of respiratory muscles. A few studies have evaluated phrenic nerve conduction, but not diaphragmatic EMG, in COPD patients. Podnar and Harlander ${ }^{7}$ found increased latencies and amplitudes, but reduced area, in 20 COPD patients compared with 27 controls. Hopkinson et al. ${ }^{14}$ did not find any significant difference between nine COPD patients and seven controls, Lu et al. ${ }^{15}$ studied only three COPD patients and found reduced CMAP amplitudes in two of them. El-Tantawi et al. ${ }^{16}$ studied 40 COPD patients (all men) and compared them with 27 matched age and height controls. He did not find any significant difference between these two groups in amplitude and the latency of phrenic CMAP (area and duration were not mentioned) using the same recording points that were used by Podnar and Harlander ${ }^{7}$ and ourselves. Our study shows a reduced CMAP area in 20 asthmatic patients compared with 27 controls. Although the CMAP area is also reduced in neuropathy and myopathy, we did not find abnormalities in diaphragm EMGs (positive waves and fibrillation potentials at rest and abnormal recruitment and motor unit potentials), and in amplitudes and latencies of the phrenic nerve conduction, that would be expected in neuropathy or myopathy. Corticoid-induced myopathy typically shows a normal EMG, except in the advanced stages, but even in a mild disease proximal weakness is present, especially in the pelvic girdle, which was not seen in our asthmatic patients ${ }^{17}$.

There is evidence of oxidative stress in the skeletal muscles of patients with chronic disease. It is hypothesized that this oxidative stress sends muscle cells into a catabolic state and that chronic exposure leads to wasting. Oxidative damage may contribute to skeletal muscle dysfunction and mark myofibrillar proteins for degradation. Concurrently, oxidants may stimulate expression and activity of skeletal muscle protein degradation pathways. These compounding factors of oxidative stress may ultimately lead to muscle wasting in chronic disease ${ }^{18}$.

The CMAP area is a neuroconduction parameter that better evaluates the bioelectric potential generation capacity (more so than amplitude). ${ }^{7}$ An increased proportion of collagen and abnormal muscle fibers have been described in the diaphragm of COPD patients ${ }^{19}$ as reduced force generation per cross-sectioned area, reduced myosin heavy chain content per half sarcomere and slower cross-bridge cycling kinetics ${ }^{20}$. Furthermore, there is a significantly increased proportion of type I muscle fibers and a reduction in the cross-sectioned area of all fiber types ${ }^{20}$. All these abnormalities are correlated with a lower CMAP area. The high CMAP amplitude described by Podnar and Harlander ${ }^{7}$ may be explained by the flattening of diaphragm muscle in COPD patients. According to volume conduction theory,

Table. The mean and 95\% confidence interval was used for the normally distributed variables, and the median was used for the non-normally distributed ones, $5 \%$ and $95 \%$ values represent centrally numeric variables that are statistically different between groups of study.

\begin{tabular}{|c|c|c|c|c|c|}
\hline Variable & $\mathrm{p}$ & Method & $\begin{array}{l}\text { Central tendency } \\
\text { measurement }\end{array}$ & Measurement disease & Measurement control \\
\hline FEV1\% & $<0.001$ & $\mathrm{~T}$ & Mean ( \pm CI95\%) & $48.37( \pm 65.11)$ & $103.81( \pm 45.76)$ \\
\hline FVC & $<0.001$ & Wilcoxon & (5\%, median, 95\%) & $(1.217,1.83,2.81)$ & $(3.25,4.38,6.44)$ \\
\hline fev/01 & $<0.001$ & Wilcoxon & (5\%, median, 95\%) & $(0.56,1.12,1.62)$ & $(2.76,2.86,5.09)$ \\
\hline FEV1 / FVC & $<0.001$ & Wilcoxon & (5\%, median, 95\%) & $(48.13,57.28,67.77)$ & $(74.71,84.78,90.17)$ \\
\hline FVC\% & $<0.001$ & Wilcoxon & (5\%, median, 95\%) & $(46.07,64.75,84.77)$ & $(81.12,104.20,150.03)$ \\
\hline Age & $<0.001$ & Wilcoxon & (5\%, median, 95\%) & $(37.95,60,70.2)$ & $(23,27,52.7)$ \\
\hline Height & $<0.001$ & $\mathrm{~T}$ & Mean ( \pm Cl95\%) & $1.59( \pm 0.17)$ & $1.72( \pm 0.08)$ \\
\hline Exp area & $<0.001$ & $\mathrm{~T}$ & Mean ( \pm Cl95\%) & $4.85( \pm 2.92)$ & $6.84( \pm 1.05)$ \\
\hline Exp duration & $<0.001$ & $\mathrm{~T}$ & Mean ( \pm Cl95\%) & $19.77( \pm 1.69)$ & $16.15( \pm 5.54)$ \\
\hline Insp area & $<0.001$ & $T$ & Mean ( \pm Cl95\%) & $4.8( \pm 2.39)$ & $6.22( \pm 0.44)$ \\
\hline
\end{tabular}

Cl: confidence interval; FEV1: forced expiratory volume in one second; FVC: forced vital capacity; Exp: expiratory; Insp: inspiratory. 

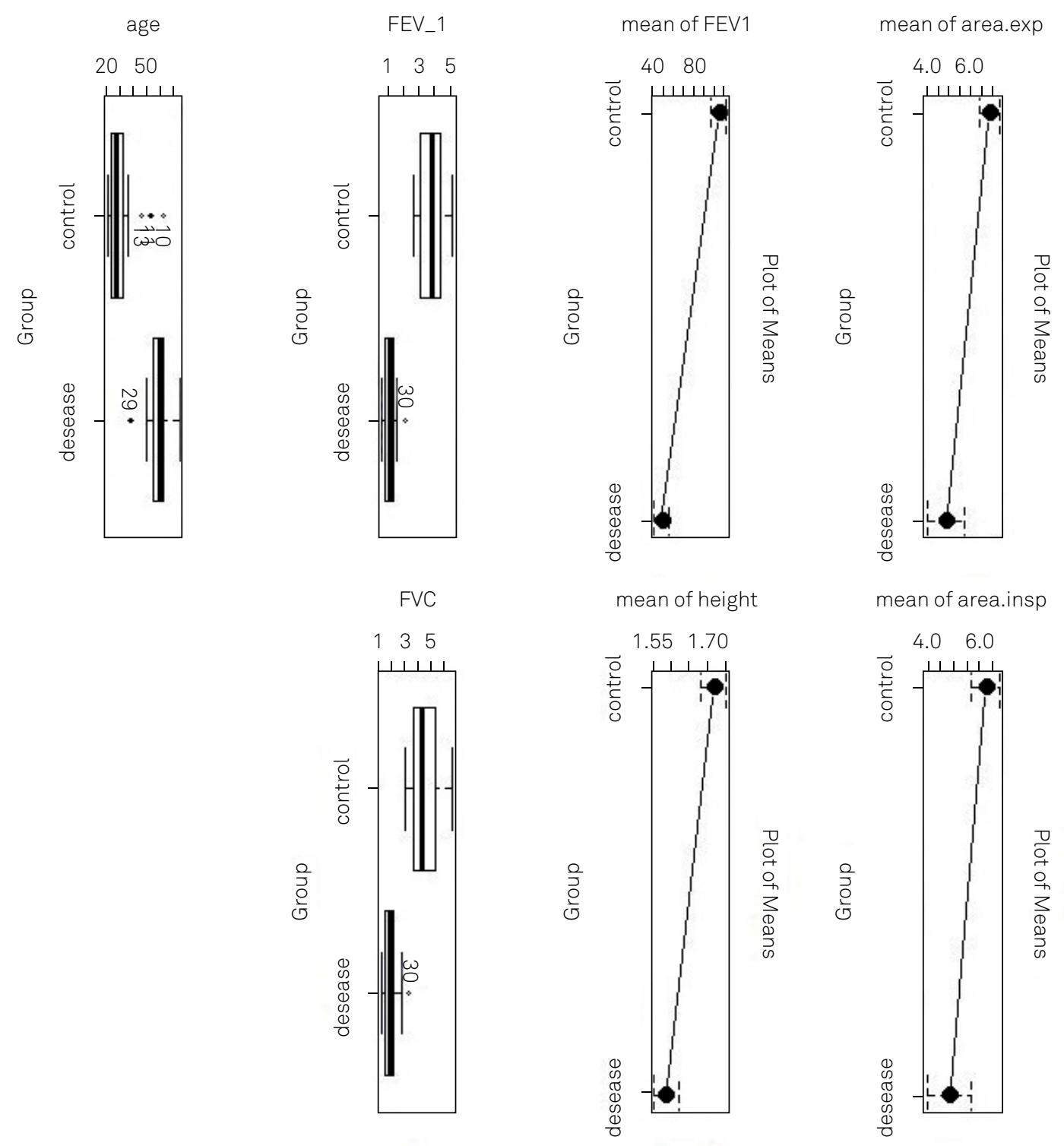

FVC

FEV1.FVC
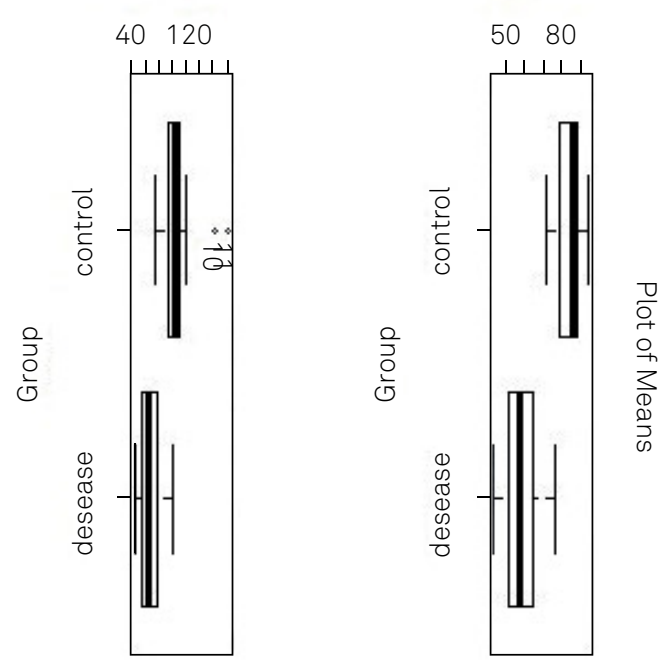

mean of duration.exp

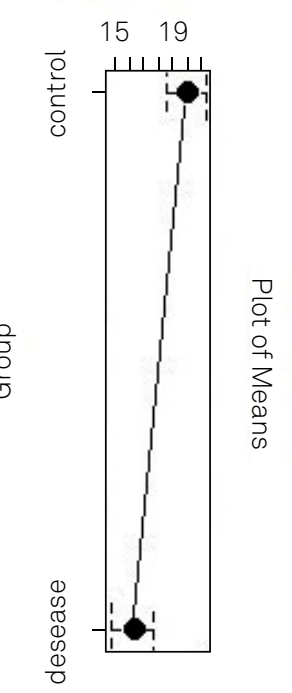


the amplitude of the CMAP is proportional to the angle the moving dipole subtends at the recording electrode. This angle is increased during the diaphragm flattening in the inspiration of normal individuals and is fixed in COPD patients ${ }^{13}$. The reduced CMAP area observed in our patients may be related to diaphragmatic fiber abnormalities, due to chronic overload of respiratory muscles or to a subclinical corticoid-induced myopathy.

One of the limitations of this study is the unmatched age and height in the control group, although none of the normative data studies have significant correlation between age, height and CMAP area ${ }^{7,13,16,21}$. Another limitation is the lack of information on asthmatic diaphragmatic muscle fiber abnormalities in the literature and, therefore, the use of COPD references in our study.

\section{CONCLUSION}

No neuromuscular disease was found among the difficult-to-treat asthmatic patients. We highlight the need for future research on histopathological analysis and quantitative motor unit potential studies of the diaphragm in asthmatic patients.

\section{References}

1. Global Initiative for Asthma, Global Initiative for Chronic Obstructive Pulmonary Disease. Global strategy for asthma management and prevention. [S.L.]: Global Initiative for Asthma; 2015. Available from: https://www.ginasthma.org/gina-reports/

2. American Thoracic Society. Proceedings of the ATS workshop on refractory asthma: current understanding, recommendations, and unanswered questions. Am J Respir Crit Care Med. 2000 Dec;162(6):2341-51. https://doi.org/10.1164/ajrccm.162.6.ats9-00

3. Chung KF, Godard P, Adelroth E, Ayres J, Barnes N, Barnes P et al. Difficult/therapy-resistant asthma: the need for an integrated approach to define clinical phenotypes, evaluate risk factors, understand pathophysiology and find novel therapies. ERS Task Force on Difficult/ Therapy-Resistant Asthma. Eur Respir J. 1999 May;13(5):1198-208.

4. Bahadori K, Doyle-Waters MM, Marra C, Lynd L, Alasaly K, Swiston J et al. Economic burden of asthma: a systematic review. BMC Pulm Med. 2009 May;9(1):24. https://doi.org/10.1186/1471-2466-9-24

5. King GG, Thamrin C. Complex lung function in severe asthma: seeing is believing. Eur Respir J. 2016 Aug;48(2):294-6. https://doi.org/10.1183/13993003.01120-2016

6. Global Initiative for Chronic Obstructive Lung Disease. Global strategy for the diagnosis, management and prevention of chronic obstructive pulmonary disease. [S.L.]: Global Initiative for Chronic Obstructive Lung Disease; 2010.

7. Podnar S, Harlander M. Phrenic nerve conduction studies in patients with chronic obstructive pulmonary disease. Muscle Nerve. 2013 Apr;47(4):504-9. https://doi.org/10.1002/mus.23617

8. Chung KF, Wenzel SE, Brozek JL, Bush A, Castro M, Sterk PJ et al. International ERS/ATS guidelines on definition, evaluation and treatment of severe asthma. Eur Respir J. 2014 Feb;43(2):343-73. https://doi.org/10.1183/09031936.00202013

9. Miller MR, Hankinson J, Busasco V, Burgos F, Casaburi R, Coates A et al. Standardization of spirometry. Eur Respir J. 2005;26:319-38. https://doi.org/10.1183/09031936.05.00034805

10. Knudson RJ, Lebowitz MD, Holberg CJ, Burrows B. Changes in the normal maximal expiratory flow-volume curve with growth and aging. Am Rev Respir Dis. 1983 Jun;127(6):725-34. https;//doi.org/10.1164/arrd.1983.127.6.725
11. Souza RB. Pressões respiratórias estáticas máximas. J Pneumol. 2002;28 Suppl3:S155-65.

12. Resman-Gaspersc A, Podnar S. Phrenic nerve conduction studies: technical aspects and normative data. Muscle Nerve. 2008 Jan;37(1):36-41. https://doi.org/10.1002/mus.20887

13. Chen R, Collins S, Remtulla H, Parkes A, Bolton CF. Phrenic nerve conduction study in normal subjects. Muscle Nerve. 1995 Mar;18(3):330-5. https://doi.org/10.1002/mus.880180311

14. Hopkinson NS, Sharshar T, Ross ET, Nickol AH, Dayer $\mathrm{MJ}$, Porcher R et al. Corticospinal control of respiratory muscles in chronic obstructive pulmonary disease. Respir Physiol Neurobiol. 2004 Jul;141(1):1-12. https://doi.org/10.1016/j.resp.2004.04.003

15. Lu Z, Tang X, Huang X. Phrenic nerve conduction and diaphragmatic motor evoked potentials: evaluation of respiratory dysfunction. Chin Med J (Engl). 1998 Jun;111(6):496-9. PMID:11245065

16. El-Tantawi GA, Imam MH, Morsi TS. Phrenic nerve conduction abnormalities correlate with diaphragmatic descent in chronic obstructive pulmonary disease. COPD. 2015;12(5):516-24. https://doi.org/10.3109/15412555.2014.993465

17. Gupta A, Gupta Y. Glucocorticoid-induced myopathy: Pathophysiology, diagnosis, and treatment. Indian J Endocrinol Metab. 2013 Sep;17(5):913-6. https://doi.org/10.4103/2230-8210.117215

18. Moylan JS, Reid MB. Oxidative stress, chronic disease, and muscle wasting. Muscle Nerve. 2007 Apr;35(4):411-29. https://doi.org/10.1002/mus.20743

19. Scott A, Wang X, Road JD, Reid WD. Increased injury and intramuscular collagen of the diaphragm in COPD: autopsy observations. Eur Respir J. 2006 Jan;27(1):51-9. https://doi.org/10.1183/09031936.06.00143004

20. Ottenheijm CA, Heunks LM, Dekhuijzen RP. Diaphragm adaptations in patients with COPD. Respir Res. 2008 Jan;9(1):12. https://doi.org/10.1186/1465-9921-9-12

21. Swenson MR, Rubenstein RS. Phrenic nerve conduction studies. Muscle Nerve. 1992 May;15(5):597-603. https://doi.org/10.1002/mus.880150511 